\title{
Prevention and treatment of ventricular dysrhythmias
}

\author{
Graeme Sloman, John Dowling, ${ }^{1}$ and Jitu Vohra ${ }^{2}$ \\ From the Cardiac Laboratory, Royal Melbourne Hospital, Victoria 3050, Australia
}

The development of coronary care units with both the appropriate trained medical and nursing staff and the electronic equipment to monitor and record the heart rhythm has led to the recognition of the high incidence of ventricular dysrhythmias. These include abnormalities of heart rate, rhythm, and conduction. The prompt treatment of these dysrhythmias has been an important factor in establishing the effectiveness of the unit (Julian, Valentine, and Miller, 1964; Goble, Sloman, and Robinson, 1966).

The great majority of patients with acute infarction when observed in the coronary care unit are found to have some form of dysrhythmia. The incidence of the various dysrhythmias varies depending on the unit's admission policy and the degree of surveillance.

A review of our recent experience in the coronary care unit at the Royal Melbourne Hospital showed that a significant ventricular dysrhythmia occurred in over 50 per cent of patients.

Information is now becoming available about the prehospital period from the onset of pain associated with acute infarction until the patient is admitted to hospital (Pantridge and Geddes, 1967; Dewar, McCollum, and Floyd, 1969; Robinson and McLean, 1970; Lown and Ruberman, 1970).

These studies show a similar high incidence of significant arrhythmias. Other studies are providing information about late deaths in hospital after discharge from the coronary care unit (Sloman et al., 1970).

The overall hospital mortality for patients developing a ventricular dysrhythmia in the coronary care unit remains high. We have found a 50 per cent mortality for patients developing ventricular fibrillation or ventricular tachycardia, and an 80 per cent mortality for patients developing ventricular standstill.

\footnotetext{
${ }^{1}$ National Heart Foundation of Australia Research Assistant.

2 Ethnor Research Fellow.
}

Therefore it behoves us to attempt to prevent these arrhythmias and thereby reduce the mortality.

In the prehospital care phase, Adgey et al. (1968) and Robinson and McLean (1970) have shown that early appropriate aggressive antiarrhythmic therapy has been responsible for salvaging patients. About 50 per cent of those patients dying in the first year after discharge from hospital die suddenly, presumably from a cardiac arrhythmia. Identification and treatment of a susceptible group of patients after acute infarction, or the administration of a suitable antiarrhythmic drug to all patients discharged from hospital, might be expected to reduce this mortality.

It is useful to divide the dysrhythmias further into the so-called minor ventricular dysrhythmias, where the alteration in rate, rhythm, or conduction does not cause a significant change in the circulatory state, and major ventricular dysrhythmias, which are those that are associated with a significant haemodynamic deterioration.

In this paper we present our current practice in the prevention and management of ventricular dysrhythmias after acute infarction.

Slow ventricular dysrhythmias after acute myocardial infarction

Suppression of impulse formation or transmission with resultant escape rhythm is responsible for ventricular bradydysrhythmias after myocardial infarction. In the discussion which follows, ventricular rhythm disturbances are considered under idioventricular tachycardia and atrioventricular block.

A slow ventricular rate in acute myocardial infarction may be associated with inability to maintain an effective cardiac output. While it is not possible to lay down the minimum ventricular rate required to maintain an adequate cardiac output in a given patient, there is considerable evidence to support the contention that a rate of less than 50 per minute generally carries an adverse prognosis (James, 1962). 
The reduced heart rate has to be compensated for by increase in stroke volume, which may not be possible because of impaired myocardial performance after myocardial infarction (Zipes, 1969). A low cardiac output in this situation may further increase myocardial anoxia and cardiac failure and thus perpetuate the vicious circle. If there is loss of atrial transport in these critically ill patients there will be further lowering of cardiac output (Braunwald, 1964).

A slow ventricular rate predisposes to the development of ectopic rhythms as a result of increased automaticity of junctional and ventricular conducting tissue. This may cause a reduction in ventricular fibrillatory threshold. Prompt prevention and treatment of slow ventricular rates may, therefore, contribute to a reduction in mortality (Lown et al., 1967).

\section{Idioventricular tachycardia}

There is considerable confusion about a suitable name for this arrhythmia. In the past it has been referred to as 'slow ventricular tachycardia', a term which is contradictory in itself. As advocated by Schamroth (1969), 'idioventricular tachycardia' appears to be a more suitable description and is based on the contention that as the usual idioventricular rhythm is about 40 per minute a rate higher than this is 'idioventricular tachycardia'.

With continuous monitoring idioventricular tachycardia is increasingly often detected in patients with acute inferior myocardial infarction (Spann et al., 1964). With periodic recording of rhythm strips, as is the current practice in most coronary care units, many instances of idioventricular tachycardia go undetected.

This dysrhythmia is observed in the presence of sinus bradycardia in patients with acute myocardial infarction. The mechanism is multifactorial (Castellanos, Lemberg, and Arcebal, 1969), but requires electrically unstable myocardium, enhanced automaticity, and loss of protection from sinus impulses. Its appearance depends on an interplay of the sinus and the ectopic ventricular rates. The ventricular rate in idioventricular tachycardia is usually between 60 and 100 per minute, and this arrhythmia appears when the sinus rate falls below the ectopic rate. The transposition between the rhythms is gradual and the ectopic rhythm appears in late diastole, as opposed to a fast extrasystolic ventricular tachycardia.

It is generally accepted that idioventricular tachycardia is usually a minor ventricular arrhythmia, and, unlike extrasystolic ventricular tachycardia, is normally not associated with
VARIABLE VENTRICULAR RATE IN IDIOVENTRICULAR TACHYCARDIA

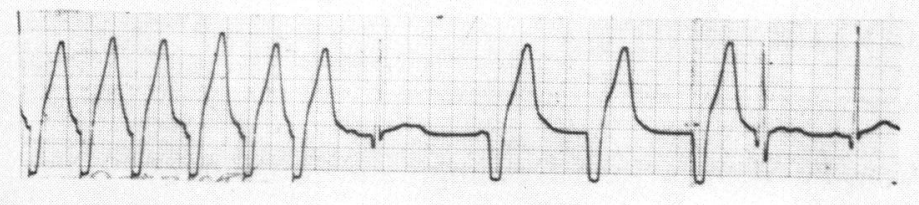

FIG. I An electrocardiogram strip demonstrating two runs of ventricular tachycardia; the second and slower run begins with a beat occurring late in diastole.

serious haemodynamic deterioration. Because the ectopic rhythm starts late in diastole and outside the vulnerable period, it does not lead to ventricular fibrillation. However, on occasion, because of a variation in exit block, the ventricular rate may increase and some reduction in cardiac output may occur (Fig. I). An ectopic rhythm may depress the dominant cardiac pacemaker by premature depolarization and may thus usurp control of the cardiac mechanism (Zipes, 1969).

In patients with hypotension, suppression of idioventricular tachycardia may raise blood pressure to a certain extent when the sinus rhythm is restored.

With these arguments in mind, it is our practice to treat idioventricular tachycardia.

Prevention As mentioned earlier, idioventricular tachycardia occurs in the presence of a slow sinus rate. Both inferior and lateral infarction may result in oedema and damage of the sinus node and its connecting pathways.

Several other factors, besides structural damage, play a part in causing sinus bradycardia. These are pericarditis, cholinergic impulses (Von Bezold-Jarisch reflex), a sense of fear and despair, sudden rise of blood pressure, hypoxia and acidosis, pain and the morphine group of analgesics, and stretch reflexes in the left ventricle and coronary sinus (James, 1969). These factors contribute to sinus bradycardia, which in turn predisposes to idioventricular tachycardia.

Prevention of idioventricular tachycardia therefore lies in increasing the sinus rate by administration of atropine. It is our practice to administer atropine sulphate intravenously in the dose of 0.3 to $1.2 \mathrm{mg}$.

Treatment Increasing the sinus rate pharmacologically or electrically is effective in control of idioventricular tachycardia. Atropine intravenously is effective in most cases, particularly where Jarisch's reflex plays a dominant part (Fig. 2). Where ineffective, and the 
patient's condition is satisfactory, the arrhythmia may be kept under observation, as it may terminate spontaneously. Where termination of the arrhythmia is necessary because of hypotension, low cardiac output, or appearance of early diastolic ectopics, atrial pacing is successful.

In patients whose idioventricular rate is relatively fast some authors recommend the careful use of lignocaine (Castellanos et al., 1969), and we have encountered occasions when this has successfully terminated idioventricular tachycardia. However, it is important to point out that administration of procainamide and quinidine in this situation may not only be ineffective but hazardous, and may lead to further bradycardia or asystole (Han, I969; Zipes, 1969).

Atrio-ventricular conduction defects in acute myocardial infarction

Atrioventricular block occurs in both inferior and anterior myocardial infarction and results from ischaemia or damage to the specialized conducting tissue.

The atrioventricular node and bundle of His receive their blood supply from the right coronary artery in more than 90 per cent of the population. Atrioventricular conduction disturbances are more frequent in inferior infarction, and when complete heart block develops in this situation lower junctional tissue initiates the rhythm.

Atrioventricular block occurring in the presence of anterior infarction implies an extensive infarct or presence of a previous inferior myocardial infarction. The escape rhythm is unstable and unreliable and the incidence of ventricular standstill and major ventricular dysrhythmia is high.

Incidence of atrioventricular conduction disturbances based on $\mathbf{4 4 6}$ patients admitted to the coronary care unit with definite acute myocardial infarction was 11.5 per cent (Brown, Hunt, and Sloman, 1969). The mortality in these patients was 33 per cent compared to overall hospital mortality of 25 per cent.

Complete heart block developed in 29 patients. There were three times as many patients with inferior infarction as with anterior infarction. The overall mortality was 45 per cent. These figures are similar to those of other groups (Sutton, Chatterjee, and Leatham, I968; Paulk and Hurst, 1966; Norris, 1969).

Prevention First degree atrioventricular block as such requires no treatment and does not influence mortality. However, first degree

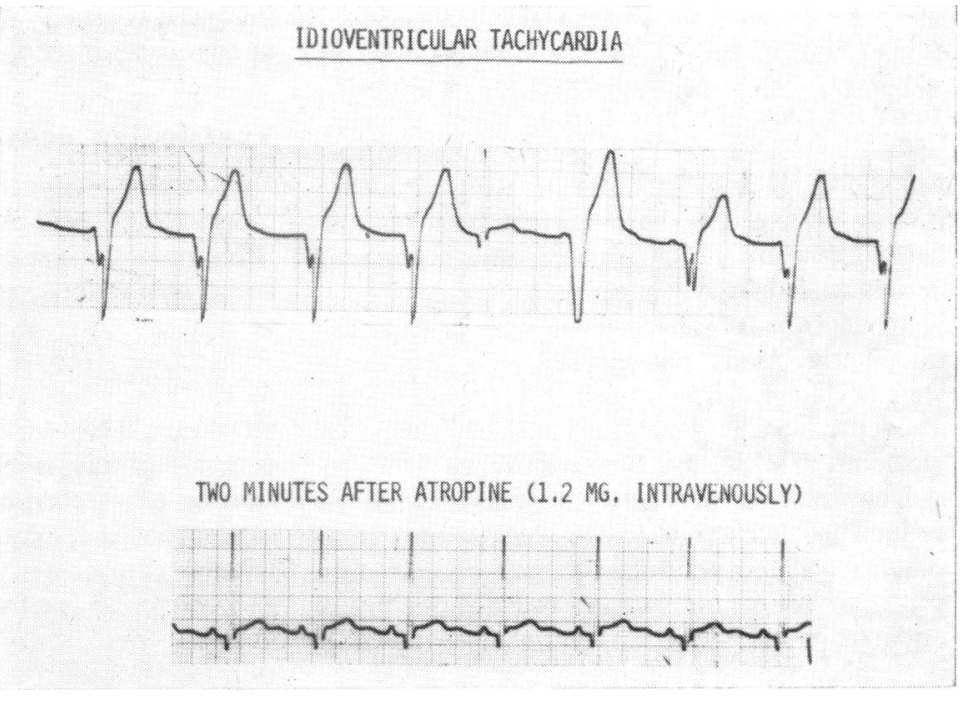

FIG. 2 The effect of atropine sulphate in controlling persistent idioventricular tachycardia.

atrioventricular block associated with bilateral bundle-branch block may progress to asystole and sudden death (Hunt and Sloman, 1969). Prophylactic insertion of a pacemaker electrode has been used in this situation. However, the mortality remains high and reflects the extent of myocardial damage.

Second degree atrioventricular block is generally not seen complicating anterior myocardial infarction, and was not by itself associated with haemodynamic deterioration or increased mortality in patients with inferior myocardial infarction. Mobitz type II block may, however, be found in patients with anterior myocardial infarction, and such patients require pacing.

Atropine is useful in increasing the ventricular rate in patients with inferior infarction and a ventricular bradydysrhythmia resulting from second degree atrioventricular block. If atropine is ineffective an isoprenaline infusion or sustained release isoprenaline (Saventrine) orally may be employed.

Treatment All patients with complete heart block, even when asymptomatic and with good output, are treated by insertion of an endocardial electrode and are paced with a demand pacemaker. The pacemaker rate is adjusted up to 90 per minute, depending upon the haemodynamic state and presence or absence of other arrhythmias. Older patients seem to fare better with a higher pacing rate.

The mortality in patients with complete 
heart block as a result of inferior infarction is only slightly higher than in patients without any heart block (Chamberlain and Leinbach, 1970). Although it is our practice to pace all patients with complete heart block, the indications for pacing in inferior infarction are mainly in patients with cardiac failure, low cardiac output, hypotension, and recurrent ventricular dysrhythmia.

In anterior infarction, even with prophylactic pacing, many patients die of cardiogenic shock (Lassers et al., 1968), and the incidence of ventricular dysrhythmia at the time of electrode positioning is quite high.

Leinbach et al. (1969) report the use of sequential atrioventricular pacing in nine patients, which produced higher cardiac output than ventricular pacing but did not influence the mortality in anterior infarction (Chamberlain and Leinbach, 1970).

Ventricular premature beats and fast ventricular dysrhythmias after acute myocardial infarction

Ventricular premature beats, ventricular tachycardia, and ventricular fibrillation are all expressions of increased ventricular irritability. In the acute stage of myocardial infarction every effort should be made to recognize and stabilize any ectopic activity in an attempt to prevent a fatal dysrhythmia from occurring. Ventricular premature beats are common, occurring in up to 75 per cent of patients in the acute stage of myocardial infarction; but at this time it is not our practice to treat isolated ventricular premature beats.

Recognition of the nature of ventricular premature beats in a particular case is important. We regard the appearance of more than one in ten beats as demanding antiarrhythmic therapy, regardless of its position in relation to the preceding beat. The presence of two ventricular ectopics together, or of impulses arising from different ventricular foci, also requires treatment. We employ for this purpose lignocaine by intravenous injection, a statim dose of 50-100 mg. or I mg./kg. followed by an intravenous infusion of $\mathrm{I} \mathrm{mg}$. per minute increased as necessary to a maximum of $4 \mathrm{mg}$. per minute. The infusion is continued for almost the entire period of observation in the coronary care unit and is succeeded by procainamide administration.

Thus, despite the minimal haemodynamic effects of such ventricular premature beats, they should be treated in order to minimize the likelihood of the appearance of more malignant ventricular dysrhythmias. If lignocaine and procainamide are found to be ineffective, then we employ beta-receptor antagonists, phenytoin sodium, or quinidine.

\section{Ventricular tachycardia}

Ventricular tachycardia is defined by the New York Heart Association as 'a succession of three or more consecutive ventricular premature contractions, recurring usually at a rate of 150-250 per minute' (New York Heart Association, 1964). We take I00 per minute as the lower limit of rate to define this dysrhythmia. Hypokalaemia, hypomagnesaemia, excess digitalis, hypoxia, and the administration of beta-receptor stimulating drugs such as isoprenaline, may induce or perpetuate ventricular ectopic activity.

Ventricular tachycardia was observed in about 15 per cent of 126 patients with infarction monitored in our coronary care unit, and carried a hospital mortality of about 50 per cent. It was more commonly associated with severe infarction. Mogensen (1970), reviewing continuous 24-hour electrocardiograms, reported a considerably higher figure and suggested the need for continuous prophylactic lignocaine therapy from the time of admission in order to lower the frequency of such episodes. Procainamide, given orally 3 -hourly in doses sufficient to maintain the plasma concentration between 4 and $6 \mathrm{mg}$./litre, has also been advocated to prevent ventricular dysrhythmias (Koch-Weser et al., I969). Only patients who were free from severe cardiac failure, shock, and atrioventricular dissociation were so treated.

The treatment of short transient episodes of ventricular tachycardia is similar to the treatment of ventricular premature beats outlined above, although procainamide or betaadrenergic receptor antagonists may be elected to be used initially or after a trial of lignocaine therapy. The dose of lignocaine may be higher for this purpose, but prolonged administration of doses such as 4-5 mg./minute may lead to drowsiness, confusion, or epileptic fits. Decreased hepatic function is particularly apt to predispose to such adverse effects. Concurrent administration of another antiarrhythmic drug such as procainamide allows lignocaine to be used more sparingly.

Other drugs that have a place in the management of recurring ventricular tachycardia are quinidine, phenytoin sodium, betareceptor antagonists such as practolol or propranolol, and bretylium tosylate. We have found the latter drug useful in a number of instances, given intravenously or by continuous infusion. Recently phentolamine has been used and has been found to be promising 
(Gould et al., 1969). If drug therapy is not adequate - that is, does not abolish sustained ventricular tachycardia - synchronized direct current countershock should be used.

Fixed rate 'overdrive' pacing has been used in the management of recurrent ventricular arrhythmias. Although the mortality remains high and is probably associated with the large size of the underlying infarction, it is our practice to combine this form of therapy with antiarrhythmic drugs. Occasionally an arrhythmia may be controlled by fixed rate pacing with only occasional capture.

Ventricular dysrhythmias should of course be distinguished from supraventricular arrhythmias with aberrant conduction. The latter may mimic ventricular tachycardia electrocardiographically if $\mathrm{P}$-waves are present owing to atrial activity independent of (because of retrograde block) underlying nodal tachycardia with aberrant ventricular conduction. In most cases where there is doubt, however, atrial activity can be identified by the insertion of an atrial exploring electrode.

\section{Ventricular fibrillation}

Primary ventricular fibrillation, occurring in the absence of shock or severe cardiac failure, had an incidence of 8 per cent in our coronary care unit and 72 per cent of the patients left hospital alive (Sloman et al., I970). An incidence of ro per cent was found for secondary ventricular fibrillation, and only 22 per cent of these patients survived to go home. The survival rate dropped to 15 per cent at three months. Primary ventricular fibrillation should be preventable, and this can only be effected by careful and prompt treatment of warning ventricular dysrhythmias, attention to underlying electrolyte, acid base, or oxygenation disturbances, and avoidance of arrhythmia-precipitating drugs. A recent report on the prophylactic effectiveness of oral lignocaine (Parkinson, Margolin, and Dickson, 1970) is of interest and deserves further study. Perhaps an orally effective, rapidly absorbed antiarrhythmic drug may be useful in the prehospital phase.

The treatment of ventricular fibrillation is immediate direct-current countershock. To this end the nursing staff is trained to accept the responsibility of identifying ventricular fibrillation and treating it. If ventricular fibrillation proves difficult to revert, underlying causes such as anoxia should be corrected where possible, and antiarrhythmic drug therapy should be reviewed.

\section{References}

Adgey, A. A. J., Geddes, J. S., Mulholland, H. C., Keegan, D. A. J., and Pantridge, J. F. (1968). Incidence, significance and management of early bradyarrhythmia complicating acute myocardial infarction. Lancet, 2, 1097.

Braunwald, E. (1964). Symposium on cardiac arrhythmias. Introduction, with comments on the hemodynamic significance of atrial systole. American fournal of Medicine, 37, 665 .

Brown, R. W., Hunt, D., and Sloman, J. G. (1969). The natural history of atrioventricular conduction defects in acute myocardial infarction. American Heart fournal, 78, 460.

Castellanos, A., Jr., Lemberg, L., and Arcebal, A. G. (1969). Mechanisms of slow ventricular tachycardias in acute myocardial infarction. Diseases of the Chest, 56, 470.

Chamberlain, D., and Leinbach, R. (1970). Editorial. Electrical pacing in heart block complicating acute myocardial infarction. British Heart fournal, 32, 2.

Dewar, H. A., McCollum, J. P. K., and Floyd, M. (1969). A year's experience with a mobile coronary resuscitation unit. British Medical fournal, 4, 226.

Goble, A. J., Sloman, J. G., and Robinson, J. S. (1966). Mortality reduction in a coronary care unit. British Medical fournal, $1,1005$.

Gould, L., Zahir, M., Shariff, M., and Guiliani, M. G. (1969). Treatment of cardiac arrhythmias with phentolamine. American Heart Fournal, 78, 189.

Han, J. (1969). Mechanisms of ventricular arrhythmias associated with myocardial infarction. American fournal of Cardiology, 24, 800.

Hunt, D., and Sloman J. G. (1969). Bundle-branch block in acute myocardial infarction. British Medical fournal, $1,85$.

James, T. N. (1962). Arrhythmias and conduction disturbances in acute myocardial infarction. American Heart fournal, 64, 416.

- (1969). Pathogenesis of arrhythmias in acute myocardial infarction. American fournal of Cardiology, 24, 79r.

Julian, D. G., Valentine, P. A., and Miller, G. G. (I964). Disturbances of rate, rhythm and conduction in acute myocardial infarction. American fournal of Medicine, 37, 915.

Koch-Weser, J., Klein, S. W., Foo-Canto, L. L., Kastor, J. A., and DeSanctis, R. W. (1969). Antiarrhythmic prophylaxis with procainamide in acute myocardial infarction. New England fournal of Medicine, 281, 1253.

Lassers, B. W., Anderton, J. L., George, M., Muir, A. L., and Julian D. G. (I968). Hemodynamic effects of artificial pacing in complete heart block complicating acute myocardial infarction. Circulation, 38, 308.

Leinbach, R. C., Chamberlain, D. A., Kastor, J. A., Harthorne, J. W., and Sanders, C. A. (I969). A comparison of the hemodynamic effects of ventricular and sequential $\mathrm{A}-\mathrm{V}$ pacing in patients with heart block. American Heart fournal, 78, 502.

Lown, B., Fakhro, A. M., Hood, W. B., Jr., and Thorn, G. W. (1967). The coronary care unit. Fournal of the American Medical Association, 199, 188.

$\longrightarrow$, and Ruberman, W. (1970). The concept of precoronary care. Modern Concepts of Cardiovascular Disease, 39, 97.

Mogensen, L. (1970). Prophylactic use of lidocaine in a coronary care unit. In Symposium of Cardiac Arrhythmias p. 695. Elsinore, Denmark.

New York Heart Association (1964). Diseases of the Heart and Blood Vessels, 6th ed. Little, Brown, Boston. 
Norris, R. M. (1969). Heart block in posterior and anterior myocardial infarction. British Heart fournal, 31, 352.

Pantridge, J. F., and Geddes, J. S. (1967). A mobile intensive-care unit in the management of myocardial infarction. Lancet, 2, 271.

Parkinson, P. I., Margolin, L., and Dickson, D. S. P. (1970). Oral lignocaine: its absorption and effectiveness in ventricular arrhythmia control. British Medical Fournal, 2, 29.

Paulk, E. A., Jr., and Hurst, J. W. (1966). Complete heart block in acute myocardial infarction: a clinical evaluation of the intracardiac bipolar catheter pacemaker. American fournal of Cardiology, 17, 695.

Robinson, J. S., and McLean, A. C. J. (I970). Mobile coronary care. Medical fournal of Australia, 2, 439.
Schamroth, L. (1969). Editorial. Idioventricular tachycardia. Diseases of the Chest, 56, 466.

Sloman, G., Dowling, J., Thompson, P., Hunt, D., Brown, R., and Ferguson, J. (1970). Prevalence of malignant arrhythmias in acute myocardial infarction. In Symposium on Cardiac Arrhythmias, p. 677. Elsinore, Denmark.

Spann, J. F., Jr., Moellering, R. C., Jr., Haber, E., and Wheeler, E. O. (1964). Arrhythmias in acute myocardial infarction. New England fournal of Medicine, 271, 427.

Sutton, R., Chatterjee, K., and Leatham, A. (1968). Heart-block following acute myocardial infarction. Lancet, 2, 645.

Zipes, D. P. (1969). The clinical significance of bradycardic rhythms in acute myocardial infarction. American fournal of Cardiology, 24, 814. 